\title{
МАРКИРОВКА МОЛОЧНОЙ ПРОДУКЦИИ: ОБЗОР МНЕНИЙ
}

\section{DAIRY PRODUCT LABELING: AN OVERVIEW OF OPINIONS}

\section{O. Yakovleva \\ G. Loktionova \\ O. Liseykina}

Summary. The article deals with the introduction of labeling of dairy products using a $Q R$ code. Foreign and domestic experience in the use of marking is presented. The opinions of experts, specialists and consumers are highlighted. Conclusions are made about the emerging economic risks and the need for more balanced approaches to the introduction of labeling due to the social significance of dairy products is noted.

Keywords: dairy industry, labeling of dairy products, opinions of experts, specialists, consumers.
Яковлева Ольга Анатольевна

К.с-х.н., дочент, ФГОБУ ВО Московская государственная академия ветеринарной медицины и биотехнологий - МВА им. К.И. Скрябина», г. Москва yakovleffo@yandex.ru

Локтионова Галина Робертовна

К.с-х.н., дочент, ФГОБУ ВО Московская государственная академия ветеринарной медицины и биотехнологий - МВА им. К. И. Скрябина», г. Москва galina.lokti@yandex.ru

Лисейкина Ольга Витальевна Старший преподаватель, ФГОБУ ВО Московская государственная академия ветеринарной медицины и биотехнологий - МВА им. К.И. Скрябина», г. Москва ofoxi73@bk.ru

Аннотация. В статье рассмотрены аспекты введения маркировки молочной продукции с помощью QR-кода. Представлен зарубежный и отечественный опыт применения маркировки. Освещены мнения экспертов, специалистов и потребителей. Сделаны выводы о возникающих экономических рисках и отмечена необходимость более взвешенных подходов к введению маркировки в силу социальной значимости молочной продукции.

Ключевые слова: молочная отрасль, маркировка молочной продукции, мнения экспертов, специалистов, потребителей.

продукции установлен 1 июня 2020 г. [2]. Позже начало обязательной маркировки было перенесено на 20 января 2021 г.

Эксперимент по маркировке начался в июле 2019 г. и должен был завершиться в начале 2020 г. Ранее Минпромторг предлагал продлить сроки эксперимента по маркировке молочной продукции до 31 августа 2020 г., что по мнению ведомства позволило бы молочной отрасли получить больше времени для отработки всех процессов и форматов взаимодействия с Центром развития перспективных технологий (ЦРПТ), являющимся оператором цифровой системой маркировки «Честный Знак».

По данным ЦРПТ общее число участников эксперимента на конец марта 2020 г. составляло 1288 компаний, при этом подавляющая часть участников - это ритейлеры [3].

Технологически маркировка молочной продукции идентична процессам маркирования других продуктов. На каждую единицу (упаковку), а в некоторых случаях более крупную тару, крепится специальная метка. Она 
представляет собой QR-код в виде квадрата с черными точками в формате Data Matrix. B нем зашифрованы все данные о товаре: наименование производителя, товара, бренд, номер декларации соответствия, срок годности и иное. Потребители смогут проверить подлинность продукции с помощью мобильного приложения «Честный знак», установленного на любой гаджет.

Россия не является первооткрывателем процедуры и технологии маркировки. Существует несколько глобальных подходов к решению задачи по созданию национальных систем обязательной маркировки товаров.

В Евросоюзе решение об обязательной маркировке построено на жесткой централизации и главенстве государства в управлении процессом. Такой подход позволяет сохранять честную конкуренцию, поскольку основной регулятор выступает в качестве гаранта чистоты рынка.

Альтернативное решение реализовано в США: на территории государства функционирует несколько систем маркировки одновременно, они конкурируют между собой.

В Китае не существует жестких правил, обязывающих участников товарооборота маркировать свой товар, однако она считается хорошей практикой в бизнесе. Поэтому производители добровольно делают небольшие взносы на поддержание данной системы контроля, так как именно они являются основными ее бенефициарами.

Ключевая цель таких систем - вытеснение с рынка контрафактной продукции - достигается достаточно быстро. Это подтверждается и российским опытом, и мировой практикой [4].

В России в настоящее время уже существуют системы маркировки для алкоголя и меховых изделий. Они продемонстрировали эффективность. Так, например, благодаря запуску обязательной маркировки шуб в 2016 г. только за год доля легального оборота изделий выросла в 10 раз. А в рамках эксперимента по маркировке лекарств было выявлено нарушений на полмиллиарда рублей и пресечены случаи вторичной продажи дорогостоящих препаратов [5].

Сейчас проходят эксперименты по маркировке товаров в нескольких отраслях. В 2019 г. обязательной стала маркировка духов, табака, шин и пневматических покрышек, фотокамер и ламп-вспышек, а также пяти групп изделий легкой промышленности, в том числе обувь, и с 1 июля 2020 г. предусмотрена обязательная маркировка лекарств.
Несмотря на заявленную благую цель и задачу маркировки молочной продукции - обеспечить население качественными продуктами, у нее оказалось очень много критиков.

Первый вопрос, который возник у экспертов, «не будет ли система маркировки дублировать работу системы «Меркурий»? На данном этапе уже ясно, что эти две системы являются единой цепью, позволяющей показать покупателю полную историю продукта — «от коровы до прилавка», так как «Меркурий» дает возможность отследить продукт от фермы до завода. А маркировка $\mathrm{QR}$-кодом позволит определить путь товара от предприятия до конечного потребителя. Уже создан и запущен единый интерфейс для работы в системе маркировки «Честный знак» и системе ветеринарного сопровождения «Меркурий» для молочной отрасли [6].

Очень важным аспектом сомнений в целесообразности введения маркировки каждой единицы продукции является расходы на внедрение проекта для производителей. Еще в начале эксперимента по оценкам ЦРПТ затраты на маркировку единицы продукции в молочной отрасли могли составлять от 1 до 8 копеек. Но в отраслевом союзе отмечают, что подобная стоимость будет актуальна только для тех, кто сможет распределить вложения на внедрение системы как минимум на 60 лет. Те же участники рынка, кто будет вынужден сразу инвестировать в оборудование для маркировки, будут тратить до 62 копеек на каждую единицу продукции. Учитывая стоимость расходных материалов, техническое обслуживание, временные затраты сотрудников и обучение персонала, по предварительным оценкам, совокупные единовременные инвестиции отрасли могут составят около 25 млрд. руб., а ежегодные затраты - около 20 млрд. руб. Позднее, анализируя результаты пилотного проекта, сумма вложений была уточнена до не менее 61,3 млрд. руб. только в первый год.

По мнению Россельхознадзора введение маркировки в большей мере скажется на стоимости дешевой продукции, где упаковочная единица стоит недорого. Как известно, сам QR-код стоит 50 копеек, к которым придется добавить и процедуру нанесения, покупку принтеров, ридеров, операционные расходы и прочее [7].

Того же мнения придерживаются и переработчики сырья. По мнению заместителя гендиректора Санкт-Петербургского молочного завода «Пискаревский» Г. Житмарева, «... результаты эксперимента пока не дают сделать вывод о готовности отрасли к маркировке». Только прямые затраты на нанесение кода оцениваются суммарно в $3 \%$ от стоимости продукции.

Технический директор компании «Курское молоко» К. Горин отмечает, что «...нет понимания, даже ориенти- 
ровочно, о стоимости полного комплекта оборудования для маркировки. Оборудование, которое предлагается установить, на 99\% импортное, крайне дорогостоящее. Дополнительно потребуются затраты на обучение персонала. При этом для глазированного сырка с отпускной ценой пять рублей рост себестоимости при маркировке составит $10 \%$. Все это грозит ростом цен, так как потянет затраты на логистику и у ритейлеров» [8].

Председатель совета директоров «Тульского молочного комбината» А. Ширинкин оценивает увеличение себестоимости на 5-6\% при введении маркировки и прогнозирует, что для многих, особенно мелких производителей это повлечет уход с рынка [9].

Таким образом, участники эксперимента в молочной отрасли подсчитали, что в среднем расходы на маркировку поднимут себестоимость их продукции примерно на $10 \%$, а прямые затраты на оборудование и нанесение маркировки могут достигнуть 3\% от себестоимости производства. Как вывод - небольшие и средние переработчики могут не справиться с такими затратами.

В Союзмолоко подчеркивают, что в нынешних экономических условиях дополнительная и нецелесообразная нагрузка отрасли не нужна. По их мнению, необходимо отказаться от введения обязательной маркировки молочной продукции. По итогам тестового нанесения кодов на предприятиях не удалось подобрать оптимальные опции нанесения и типы оборудования для многих видов упаковки. Все производственные линии обследованных предприятий нуждаются в дооснащении. Некоторые решения приводят к существенному замедлению линий (вплоть до 50\%), что негативно отразится на производительности всей отрасли [10]. Это ставит под угрозу стабильность поставок отечественной молочной продукции. Дополнительные затраты на маркировку приведут к снижению доступности качественной молочной продукции и росту себестоимости производства продукции минимум на 3-4\% и, как следствие,- к повышению цен для потребителей.

Производители упаковки предупреждают, что необходимость инвестиций и замедление скорости печати приведут также к росту стоимости упаковочных решений. Кроме того, до текущего момента не проводилось тестирования логистических операций, хранения и учета маркированной продукции. В среднем чтобы оснастить одну производственную линию требуется от 4 млн. до 10 млн. руб. При этом поставщики оборудования не гарантируют стопроцентную считываемость кодов, и часть продукции должна быть списана, а это дополнительные потери бизнеса [11].

Таким образом, все эксперты и представители бизнеса однозначно утверждают, что из-за маркировки неиз- бежно повышение цены на готовую продукцию, потому что за каждый уникальный код на единицу продукции придется заплатить переработчикам, а те, в свою очередь, переложат свои затраты на потребителя. Кроме этого, они делают заключение, что предложенная система не справляется с заявленными функциями, так как не обладает специфическими характеристиками, направленными на противодействие обороту фальсифицированной продукции, такими, как контроль сырья и состава продукции. При этом отмечая, что есть специальные надзорные органы, у которых должна быть возможность привлекать недобросовестных производителей к уголовной, а не только административной ответственности.

Здесь интересна точка зрения потребителей. В Российской Федерации потребление молока и молочных продуктов в среднем на человека составляет 81,7\% от рациональной нормы, при этом доля расходов на покупку продуктов питания в потребительских расходах занимает около трети, доля молока и молочных продуктов в них составляет около $17 \%$.

По результатам опросов ВЦИОМ около двух третей респондентов за введение маркировки: на продуктах питания (47\%), молочной продукции (23\%), товарах и продуктах для детей (18\%), на алкоголе (17\%), на мясной и рыбной продукции (14\%). Большинство респондентов (92\%) считают, что производители контрафакта должны нести административную или уголовную ответственность, 94\% также поддерживают ответственность для государственных органов, допустивших производство или продажу нелегальной продукции, 83\% выступают за введение ответственности для продавцов [12].

Это однозначно говорит о существующем в обществе запросе на безопасность и качество потребления, а также на реальную ответственность производителей и продавцов нелегальной продукции.

При этом около трети опрошенных потребителей готовы платить, но не более 5\% роста стоимости продуктов питания, $18 \%$ респондентов - свыше 5-10\% от стоимости и почти половина опрошенных категорически не готовы платить больше из-за введения маркировки за продукты [13].

Мнение экспертов и специалистов, отмечающих неготовность отрасли и возникающие в связи со значительными вложениями риски, с одной стороны, и неготовность населения взять на себя дополнительные траты, с другой стороны, позволяют сделать вывод о том, что в сложившихся экономических условиях введение маркировки на молочную продукцию нельзя рассматривать своевременным и целесообразным. Механизм, в силу социальной значимости молочной продукции, требует дополнительной проработки и уточнения. 
ЛИТЕРАТУРА

1. Сайт Правительства РФ. [Электронный ресурс]. Режим доступа: URL: http://gov.garant.ru/SESSION/PILOT/main.htm (дата 0бращения 19.04.2020)

2. Сайт Правительства РФ. [Электронный ресурс]. Режим доступа: URL: http://government.ru/docs/38350/(дата обращения 19.04.2020)

3. Сайт «Честный знак». [Электронный ресурс]. Режим доступа: URL: https://честыйзнак.рф/business/projects/dairy/ (дата 0бращения 19.04.2020)

4. Закон об обязательной маркировке: мировой опыт и российские реалии. [Электронный ресурс]. Режим доступа: URL: https://infostart.ru/journal/news/ uchet-nalogi-pravo/zakon-ob-obyazatelnoy-markirovke-mirovoy-opyt-i-rossiyskie-realii_977584/ (дата обращения 20.04.2020)

5. Все о маркировке товаров. [Электронный ресурс]. Режим доступа: URL: https://kontur.ru/articles/5365 (дата обращения 18.04.2020)

6. В молочной отрасли заработал единый интерфейс системы маркировки и «Меркурий»//DairyNews.ru [Электронный ресурс]. Pежим доступа: URL: https:// www.dairynews.ru/news/v-molochnoy-otrasli-zarabotal-edinyy-interfeys-sis.html (дата обращения 18.04.2020)

7. Промежуточные результаты и мнение о маркировке молочных товаров. [Электронный ресурс]. Режим доступа: URL: https://меркурий-россельхознадзор. рф/блог/промежуточные-результаты-и-мнение-о-м/ (дата обращения 20.04.2020)

8. Производители «молочки» оценили эксперимент по маркировке товаров. [Электронный ресурс]. Режим доступа: URL: https://ria.ru/20200203/1564174352. html (дата обращения 19.04.2020)

9. В Госдуме обсудили результаты эксперимента по маркировке молочной продукции. [Электронный ресурс]. Режим доступа: URL: https://milknews.ru/ longridy/V-Gosdume-obsudili-rezultaty-po-markirovke-molochnoj-produkcii.html (дата обращения 19.04.2020)

10. Союзмолоко просит перенести маркировку молочной продукции до конца эпидемии коронавируса. // DairyNews.ru [Электронный ресурс]. Режим доступа: URL: https://www.dairynews.ru/news/soyuzmoloko-prosit-perenesti-markirovku-molochnoy-.html (дата обращения 19.04.2020)

11. Артем Белов: Союзмолоко по-прежнему убеждено, что обязательная маркировка молочному рынку не нужна. // DairyNews.ru [Электронный ресурс]. Режим доступа: URL: https://www.dairynews.ru/news/artem-belov-soyuzmoloko-po-prezhnemu-ubezhdeny-cht.html (дата 0бращения 19.04.2020)

12. ВЦИОМ. Аналитический обзор. [Электронный ресурс]. Режим доступа: URL: https://wciom.ru/index.php?id=236\&uid=10138 (дата 06ращения 20.04.2020)

13. Россияне готовы платить за белый творог, а не за серый творожный продукт. [Электронный ресурс]. Режим доступа: URL: https://yandex.ru/ turbo?text=http\%3A\%2F\%2Fwww.ng.ru\%2Feconomics\%2F2020-02-04\%2F100_milk040220.html (дата 0бращения 20.04.2020)

(с) Яковлева Ольга Анатольевна ( yakovleffo@yandex.ru),

Локтионова Галина Робертовна ( galina.lokti@yandex.ru ), Лисейкина Ольга Витальевна ( ofoxi73@bk.ru ).

Журнал «Современная наука: актуальные проблемы теории и практики»

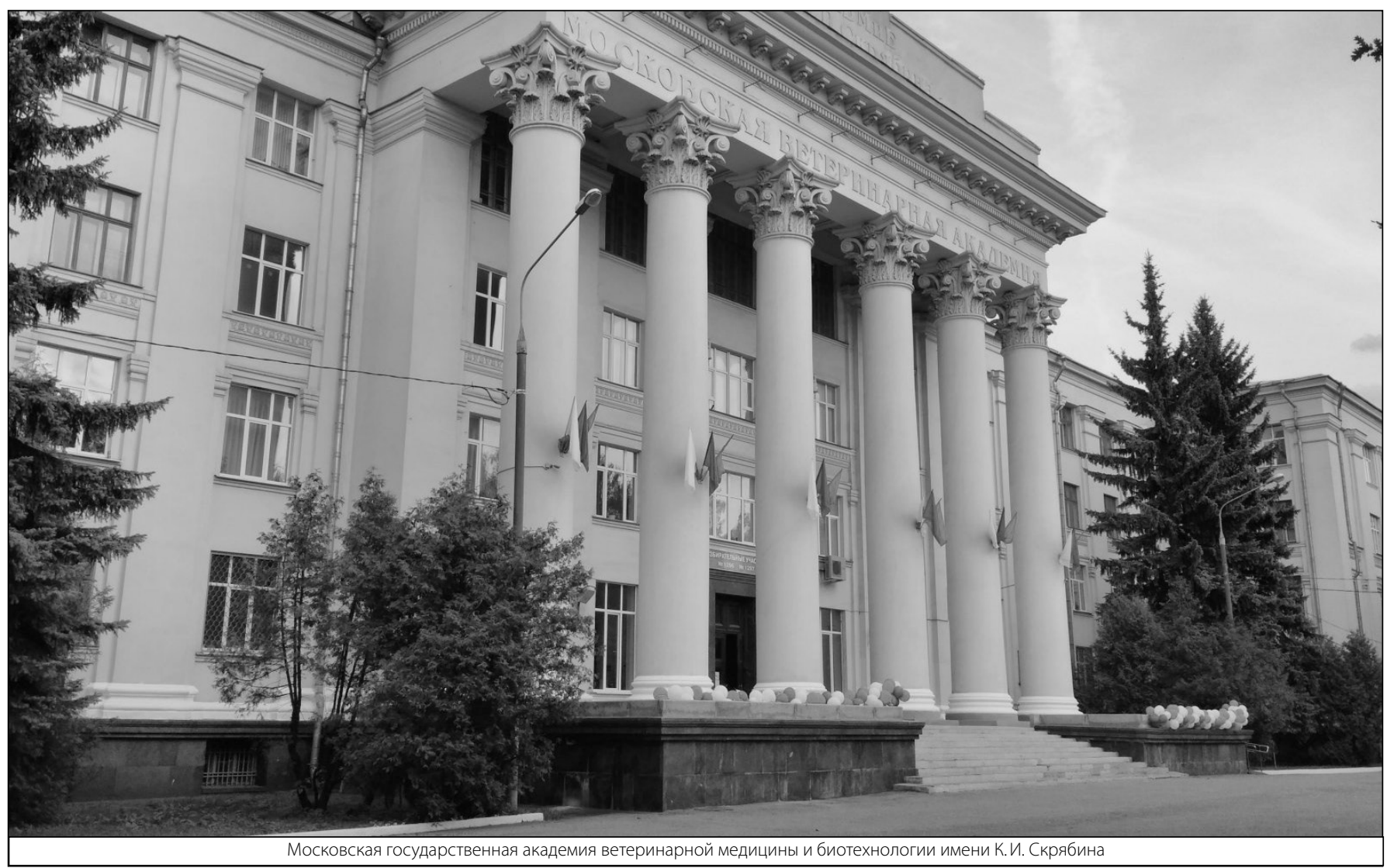

